\title{
Performance Investigation of Polymer Isolator on Non-Soluble Pollutant of Distribution Sub Station
}

\author{
Sonong ${ }^{1}$, A. M. Shiddiq Yunus ${ }^{2}$, Herman Nawir ${ }^{3}$, Muhammad Ruswandi Djalal ${ }^{4}$ \\ \{sonong@poliupg.ac.id ${ }^{1}$, shiddiq@poliupg.ac.id ${ }^{2}$, herman.nawir@poliupg.ac.id ${ }^{3}$, wandi@poliupg.ac.id ${ }^{4}$ \} \\ ${ }^{1,2}$ Energy Conversion Study Program, Department of Mechanical Engineering, Politeknik Negeri \\ Ujung Pandang, Indonesia. 90245 \\ ${ }^{3,4}$ Power Generation Engineering Study Program, Department of Mechanical Engineering, Politeknik \\ Negeri Ujung Pandang, Indonesia. 90245
}

\begin{abstract}
Isolator has an important role as a separator of lived voltage system with unlived voltage system in distribution and transmission line. It is also used as wire support in distribution and transmission line. The main usual problem in an isolator is the pollutant layer on the isolator surface. The pollutant layer on the isolator surface could lead to breakdown voltage that might harm the electrical systems and human being. The polluted isolator can be conducted by Equivalent Salt Deposit Density (ESDD) and Non-Soluble Deposit Density (NSDD). The NSDD is material that capable of absorbing water and binding the salt pollutant on the isolator surface, this could prevent the maximum natural cleaning process during rainy session.
\end{abstract}

Keywords: Breakdown Voltage, ESDD, NSDD, Pollutant.

\section{Introduction}

Transmission and distribution lines are two important parts in delivery electric power from power plants to the consumers. Therefore, it is important to maintain their reliability to guarantee the continuity of power supply [1]-[3]. It is inevitable that a healthy transmission line should be maintained properly based on the surrounding condition such as the influence of nearby cement industry, close to a beach, forest, etc. Moreover, to support the reliability of smart grid system, where renewable based power plants are involved such as wind and PV [4]-[6], a connected transmission line must be always in robust condition [7].

One important part of the transmission and distribution line is isolator. An isolator is used to separate the lived voltage system with the non-lived one. For the last decades, polymer isolator type has been popular to be used in transmission and distribution line due to its some advantages including hydrophobic characteristic, better thermal and dielectric characteristic, lighter, mechanically stronger than ceramic and glass types [8]-[10]. However, it is vulnerable to environmental impacts such as UV radiation, temperature, humidity, rain, and high pollution, etc [11], [12].

The main problem that usually occurs on isolator is the pollutant layer that might cover the isolator surface. This pollutant might cause current leakage and breakdown voltage. Compared to soluble pollutant, non-soluble pollutant could absorb water and bind the salt on the isolator surface. This condition cause the natural clean of rain does not use to clean the pollutant on the isolator surface [13]-[15]. 
The level of pollution can be categorized as shown in Table 1.

Table 1. Level of Pollution

\begin{tabular}{|c|c|}
\hline Pollution Level & Example and Environment Characteristic \\
\hline Light & $\begin{array}{l}\text { - Non-Industrial Place with a low density of } \\
\text { residential houses } \\
\text { - Agriculture Varsity } \\
\text { - } \quad \text { Mountain Varsity }\end{array}$ \\
\hline Medium & $\begin{array}{l}\text { - Medium industrial activity with low } \\
\text { pollution } \\
\text { - The high industrial and residential density } \\
\text { with high wind and rain }\end{array}$ \\
\hline Heavy & $\begin{array}{l}\text { - The very high density of industrial activities } \\
\text { - Large place but very close to a beach } \\
\text { - Desert place with very low rainy session }\end{array}$ \\
\hline
\end{tabular}

\section{Research Methodology}

In this paper, there is three analysis are employed; chemical analysis, physics analysis, and electrical analysis. The polymer isolator $2.0 \mathrm{kV}$ is taken from two places; 1) cement industry close to a mountain, 2) polymer isolator at the sub-station close to a beach which is very vulnerable with the non-soluble pollutant. The research steps are as follows:

a. Checking Chemical Composition on The Pollutant

To obtain the chemical compound of the pollutant, An Atomic Absorption Spectroscopy (AAS) is used.

b. Conductivity Measurement of The Pollutant

To measure the conductivity, TDScan IV is employed. This device has a resolution of $\quad 0.1$ $\mathrm{mS}$ with an error margin of $2 \%$. This device is equipped with Automatic Temperature Compensation (ATC), therefore obtained data does not require to be re-converted.

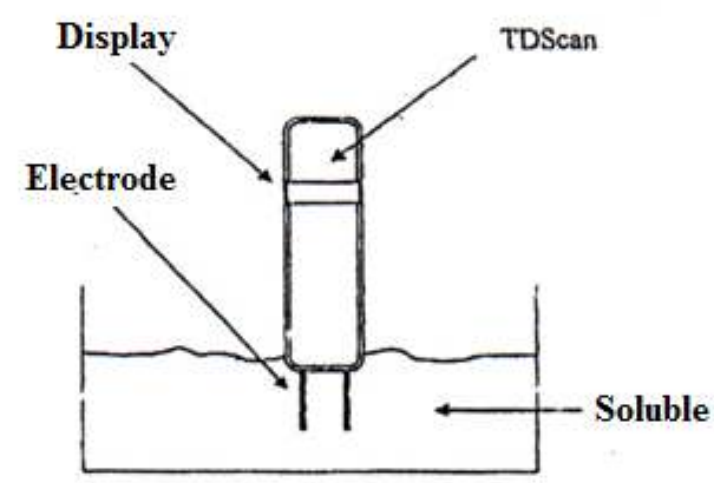

Fig. 1. A typical system of TDScan IV 
To obtain an accurate conductivity result, mineral water is used where its conductivity is 0.2 $\mu \mathrm{S} / \mathrm{cm}$.

c. Physical Measurement (Contact Angle) and Analysis.

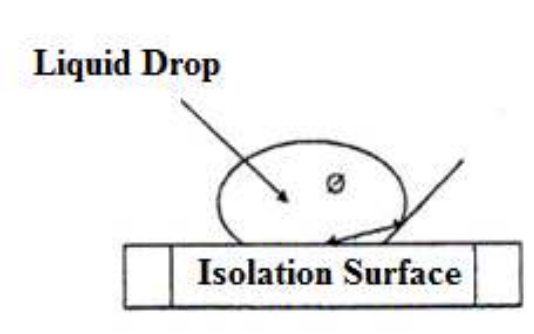

\section{Camera}

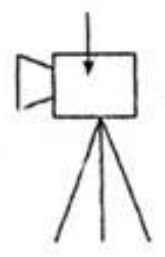

Fig. 2. Contact Angle Measurement Scheme

d. Electrical Characteristic Measurement and Analysis

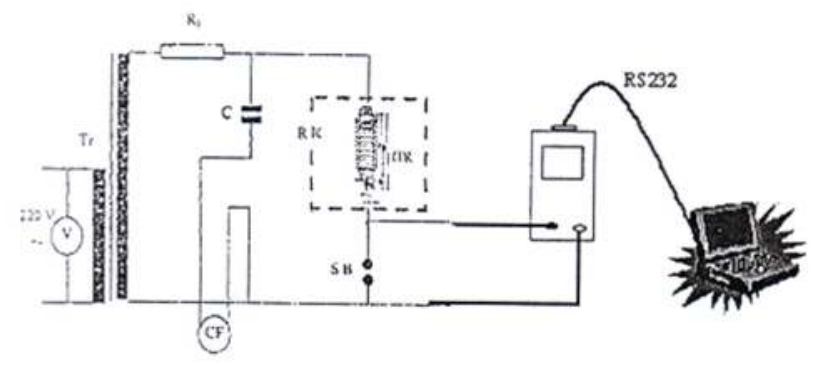

Fig. 3. Test Configuration of Conductivity Measurement

Legend of Fig. 3 as follows:

$\mathrm{Tr}$ : High voltage transformer, $220 \mathrm{~V} / 100 \mathrm{kV}$

C : High voltage capacitor, $100 \mathrm{pF}$

$\mathrm{CF}$ : Peak voltage measurement of Chubb \& Fortescue

SB : Ball gaps, distance: $1 \mathrm{~cm}$

$\mathrm{R}_{1}$ : short circuit transformer protection, $10 \mathrm{M} \mathrm{ohm}$

$\mu \mathrm{A} \quad$ : micro amperemeter connected to a computer

RK : fog room equipped with steam injection

ITR : Tested isolator, polymer, and PIN Post $20 \mathrm{kV}$.

e. Voltage Characteristic Measurement and Analysis 


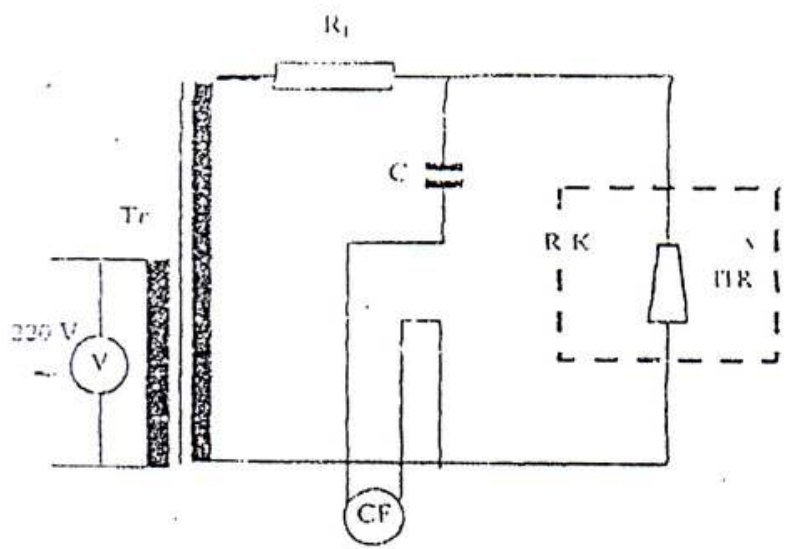

Fig. 4. Test Configuration of Breakdown Voltage

Legend of Fig. 4 as follows:

$\mathrm{Tr}$ : High voltage transformer, $220 \mathrm{~V} / 100 \mathrm{kV}$

$\mathrm{C}$ : High voltage capacitor, $100 \mathrm{pF}$

$\mathrm{CF}$ : Peak voltage measurement of Chubb \& Fortescue

$\mathrm{R}_{1}$ : short circuit transformer protection, $10 \mathrm{M}$ ohm

ITR : Tested isolator, polymer, and PIN Post $27 \mathrm{kV}$

\section{Results and Discussion}

\subsection{Chemical Compound}

Table 2 shows the composition of the pollutant of sub-station isolator. The sub-station isolator sample is taken from sub-station PT. Semen Tonasa, located at South Sulawesi, Indonesia.

Table 2. Chemical Compound Contents of Pollutant

\begin{tabular}{|l|l|c|}
\hline \multirow{2}{*}{\multicolumn{1}{|c|}{ Compound }} & \multicolumn{2}{c|}{$\begin{array}{c}\text { Example and Environment } \\
\text { Characteristic }\end{array}$} \\
\cline { 2 - 3 } & $\begin{array}{c}\text { Sub-Station } \\
\text { Isolator }\end{array}$ & Kaolin \\
\hline Sulfur $(\mathrm{S})$ & 0.007 & 0.002 \\
\hline Seng $(\mathrm{Zn})$ & 0.01 & 0.01 \\
\hline Natrium $(\mathrm{Na})$ & 0.15 & 0.43 \\
\hline Fosfor $(\mathrm{P})$ & 0.309 & 0.309 \\
\hline Aluminum $(\mathrm{Al})$ & 3.62 & 4.56 \\
\hline Besi $(\mathrm{Fe})$ & 0.41 & 0.001 \\
\hline Kalsium $(\mathrm{Ca})$ & 0.26 & 9.41 \\
\hline Silicon $(\mathrm{Si})$ & 0.102 & 0.002 \\
\hline
\end{tabular}




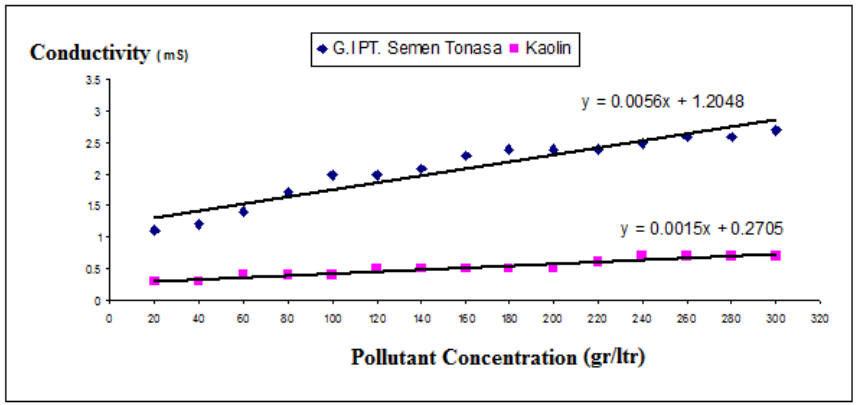

Fig. 5. Comparison results of conductivity level of both tested isolators

As can be seen in Fig. 5, conductivity value of pollutant from Sub Station Semen Tonasa is larger than Kaolin pollutant comparator. It shows that the level of pollutant surrounding substation Semen Tonasa is in the alert level for workers.

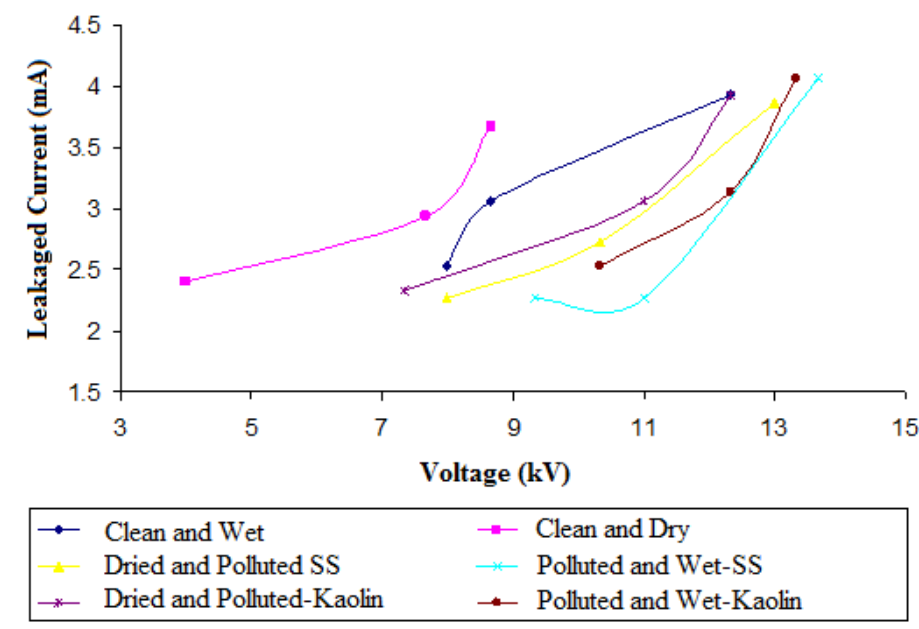

Fig. 6. Comparison of polymer isolator in several conditions (Note: SS stands for Sub-Station of Semen Tonasa)

Figure 6 exhibits the comparison graph of various condition applied to Polymer Isolator for both isolator SS-Semen Tonasa and Kaolin. Clean and Dry condition giving information that with a small increase of applied voltage $(\mathrm{kV})$, it will cause a significant leakage current. Meanwhile, the condition of all dried and polluted of SS and Kaolin are similar where larger leakage current is achieved in between $7-13 \mathrm{kV}$. Condition of polluted and wet of SS gives more leakage current after tested with almost $14 \mathrm{kV}$.

\section{Conclusion}

From obtained results of all physical and chemical tests, it can be draw conclusion that:

1. The conductivity of polymer isolator from sub-station (SS) PT. Semen Tonasa is larger than the Kaolin due to the conductivity contents of pollutant surrounding substation of PT. Semen Tonasa is larger than Kaolin. 
2. Leakage current is larger in wet condition compared to the dried one, as a soluble pollutant in wet condition is much more conductive than the dried condition

3. It is important to regularly check and re-clean the potentially polluted polymer around substation PT. Semen Tonasa to avoid any large leakage current that might damage the substation facilities and harm human life.

\section{Acknowledgments}

Authors would like to thanks Politeknik Negeri Ujung Pandang to support this research.

\section{References}

[1] M. F. Ishac, et al.: Life Extension of an Existing Transmission Line. 7Th International Conference on Transmission and Distribution Construction, Operation and Live-Line Maintenance. Pp. 17-23. doi: 10.1109/TDCLLM.1995.485031 (1995)

[2] Zili Xu, et al.: Single-Terminal Fault Location Scheme Based on the Fault Transient Characteristic of Arc for Four-Parallel Transmission Lines on the Same Tower. International Conference on Advanced Power System Automation and Protection. pp. 440-444. doi: 10.1109/APAP.2011.6180442 (2011)

[3] M. Saini., et al.: Pengembangan Peralatan Simulasi Peralatana Aliran Daya Berbasis Fast Decoupled-Dependent Newton-Rapshon dengan Program Interface-Based Delphi. INTEK: Jurnal Penelitian Vol.4. No. 1. pp. 34-41. doi: 10.31963/intek.v4i1.91 (2017)

[4] Yunus, A. M. S., Abu-Siada, A., and Masoum, M. A. S.: Effects of SMES on Dynamic Behaviors of Type D- Wind Turbine-Grid Connected during Short Circuit. IEEE Power and Energy Society Meeting. pp. 1-6. Doi: 10.1109/PES.2011.6039276 (2011)

[5] Mizuno, Y, et al.: A New Approach of Load Rejection in Fault of PV Output in Smart Grid. International Conference on Smart Grid. pp. 246-253. doi: 10.1109/ISGWCP.2018.8634535 (2018)

[6] Shiddiq Yunus, A. M., Abu-Siada, A., and Masoum, M. A. S.: Effect of SMES Unit on the Performance Type-4 Wind Turbine Generator During Voltage Sag. IET Conference on Renewable Power Generation. pp. 1-4. doi: 10.1049/cp.2011.0137 (2011)

[7] M. J. B. Reddy, D. V. Rajesh, D.K. Mohanta: Robust Transmission Line Fault Classification using Wavelet Multi-Resolution Analysis. Computer and Electrical Engineering. Vol 39, Issue 4, pp. 1219-1247. doi:/10.1016/j.compeleceng.2013.02.013 (2013)

[8] S. Manjang, I. Abduh: Leakage Current Patterns on Artificially Polluted Porcelain and Polymer Insulator. 8th International Conference on Properties and Applications of Dielectric Materials. pp. 102-105. doi: 10.1109/ICPADM.2006.284210 (2006)

[9] T. Tanahashi, et al.: Effect of Insulator Configuration on Ageing Deterioration of Polymer Insulators. Electrical Insulation Conference (EIC). doi: 10.1109/EIC.2011.5996125 (2011)

[10] S. Manjang, Mustamin, M. Nagao: Characteristics of High Voltage Polymer Insulator under Accelerated Artificial Tropical Climate Multi Stress Aging. International Symposium on Electrical Insulating Materials. pp. 221-224. doi: 10.1109/ISEIM.2011.6826389 (2011)

[11] B. K. Gautam, et al.: Effect of Wetting Conditions on The Contamination Flashover Voltages of Polymer Insulators. 8th International Conference on Properties and Applications of Dielectric Materials. pp. 538-541. doi: 10.1109/ICPADM.2006.284234 (2006)

[12] http://www.inmr.com/non-soluble-surface-deposits-on-insulators/ (Accessed: April 2019)

[13] R. Sundararajan, R. S. Gorur: Role of non-soluble contaminants on the flashover voltage of Porcelain Insulators. IEEE Transaction on Dielectric and Electrical Insulation. Vol. 3 Issue: 1. pp. 113-118. doi: 10.1109/94.485522 (1996) 
[14] S. Sundhar: Influence of non-soluble contaminants on Flashover Performance of Artificially Contaminated Polymer Insulators. IEEE Conference on Electrical Insulation and Dielectric Phenomena. pp. 657-662. doi: 10.1109/CEIDP.1994.592044 (1994)

[15] B. K. Gautam, et al.: Effect of Wetting ConditioNon-Soluble Contaminants on Flashover Voltages of Hydrophobic Polymer Insulators. 8th International Conference on Properties and Applications of Dielectric Materials. pp. 534-537. doi: 10.1109/ICPADM.2006.284233 (2006) 